Boise State University

ScholarWorks

$1-15-2010$

Effects of Small Increases in Corticosterone Levels on Morphology, Immune Function, and Feather Development

Michael W. Butler

Boise State University

Lynda L. Leppert

Alaska Sea Life Center

Alfred M. Dufty Jr.

Boise State University 


\section{Effects of Small Increases in Corticosterone Levels on Morphology, Immune Function, and Feather Development}

\author{
Michael W. Butler ${ }^{1, \star}$ \\ Lynda L. Leppert ${ }^{2, \dagger}$ \\ Alfred M. Dufty Jr. ${ }^{1, *}$ \\ ${ }^{1}$ Department of Biological Sciences, Boise State University, \\ Boise, Idaho 83725; ${ }^{2}$ Alaska Sea Life Center, P.O. Box 1329, \\ Seward, Alaska 99664
}

Accepted 5/24/2009; Electronically Published 11/24/2009

\begin{abstract}
Stressors encountered during avian development may affect an individual's phenotype, including immunocompetence, growth, and feather quality. We examined effects of simulated chronic low-level stress on American kestrel (Falco sparverius) nestlings. Continuous release of corticosterone, a hormone involved in the stress response, can model chronic stress in birds. We implanted 13-d-old males with either corticosterone-filled implants or shams and measured their growth, immune function, and feather coloration. We found no significant differences between groups at the end of the weeklong exposure period in morphometrics (mass, tarsus, wing length, and asymmetry), immunocompetence (cutaneous immunity, heterophil/lymphocyte ratio, and humoral immunity), or feather coloration. One week subsequent to implant removal, however, differences were detected. Sham-implanted birds had significantly longer wings and a reduced level of cutaneous immune function compared with those of birds given corticosterone-filled implants. Therefore, increases of only $2 \mathrm{ng} / \mathrm{mL}$ in basal corticosterone titer can have small but measurable effects on subsequent avian development.
\end{abstract}

\section{Introduction}

Birds have determinate growth, and therefore perturbations during the nestling period may have physiological (Dufty et al. 2002) or morphometric (see Metcalfe and Monaghan 2001) consequences during subsequent life stages. For example, lim-

\footnotetext{
${ }^{*}$ Corresponding author. Present address: School of Life Sciences, Arizona State University, Tempe, Arizona 85287; e-mail: mike.butler@asu.edu.

'Present address: National Wildlife Health Center, P.O. Box 46622, Madison, Wisconsin 53744; e-mail: uunica@gmail.com.

${ }^{\ddagger}$ E-mail: adufty@boisestate.edu.
}

Physiological and Biochemical Zoology 83(1):78-86. 2010. (C) 2010 by The University of Chicago. All rights reserved. 1522-2152/2010/8301-8171\$15.00 DOI: $10.1086 / 648483$ iting access to important food resources can reduce the growth rate of nestlings (Dawson and Bidwell 2005) and alter song development in adults (Nowicki et al. 2002). Hormones can have an effect as well; for example, corticosterone reduces the amount of pheomelanic coloration in developing barn owls Tyto alba (Roulin et al. 2008). Here, we examine how chronically elevated levels of the hormone corticosterone during the nestling stage affect American kestrel (Falco sparverius; hereafter, kestrels) phenotype during the nestling stage, the fledgling stage, and, in the case of feather phenotype, the first breeding season.

Corticosterone (CORT), a glucocorticoid hormone that helps regulate biological energy substrates, is one of several hormones upregulated during periods of stress (Sapolsky et al. 2000). During short-term stressors, it increases gluconeogenesis, foraging behavior, and escape behavior (Wingfield et al. 1998). Lengthier exposure to CORT, however, reduces nestling growth rates (Spencer et al. 2003; Hayward and Wingfield 2004), reduces nestling body condition (Sockman and Schwabl 2001), increases begging rate (Kitaysky et al. 2001), and is immunosuppressive (Buchanan 2000; Saino et al. 2003). Chronically elevated CORT during the nestling stage can have effects that last into adulthood, such as reduced song attractiveness (Spencer et al. 2005) and dominance rank (Spencer and Verhulst 2007).

To determine whether a small but significant increase in CORT negatively affects the development of the immune system or plumage, we implanted 13-d-old nestling male kestrels with either CORT or sham silastic tubing implants and measured their food consumption, body mass, morphometrics, phytohemagglutinin (PHA)-induced immune response, humoral immunity, ratio of heterophils to lymphocytes $(\mathrm{H}: \mathrm{L})$, and feather coloration. We compared the two groups twice: first at the end of the weeklong exposure period, to determine the immediate effects of a small increase in circulating CORT, and then $1 \mathrm{wk}$ after implant removal (when the kestrels were almost ready to fledge), to observe any delayed or persisting effects of nestling exposure to CORT.

We generated several hypotheses regarding how chronically increased levels of CORT would affect kestrel development. Increased levels of CORT can decrease growth rate (Spencer et al. 2003; but see Kitaysky et al. 2003). Therefore, we hypothesized that daily feeding rates and, consequently, body mass might be adversely affected by exogenous CORT. We also measured fluctuating asymmetry (Whitaker and Fair 2002), which is a deviation from equal size in a normally bilaterally symmetrical morphological trait (Balmford et al. 1993; Watson and Thornhill 1994). Fluctuating asymmetry is a measure of de- 
velopmental stability (Clarke 1995), and we predicted that CORT treatment would increase fluctuating asymmetry.

Because CORT inhibits the immune system during periods of prolonged exposure (Apanius 1998), we hypothesized that kestrels exposed to chronically increased levels of CORT would display lower levels of immunocompetence. There are multiple methods to measure immune function, and Salvante (2006) recommends examining more than one aspect of the immune system to measure immunocompetence more accurately. We measured humoral immunity, which has been positively related to multiple life-history traits (Hasselquist et al. 1999; Hanssen et al. 2004; Ekblom et al. 2005; Amat et al. 2007). We also used a PHA challenge, which has commonly been used as a proxy for cell-mediated immunity and reflects individual quality (Poiani et al. 2000; Navarro et al. 2003; Cichoń and Dubiec 2005; but see Tschirren et al. 2003). However, it has recently been shown that this technique does not measure cell-mediated immunity per se but rather swelling due to multiple immune cell infiltrations, including innate cell lines in addition to lymphocytes (Martin et al. 2006), thus reflecting cutaneous immune function. Last, we measured $\mathrm{H}: \mathrm{L}$, because higher $\mathrm{H}: \mathrm{L}$ has been linked to chronic stress (Gross and Siegel 1982; Ots et al. 1998), lower index of body condition (Suorsa et al. 2004), and suppression of cell-mediated (Ilmonen et al. 2003) and humoral immunity.

Colorful feathers can play an important role in mate choice (Andersson et al. 1998) as honest indicators of individual quality (Doucet and Montgomerie 2003; Garvin et al. 2008). Increased levels of CORT model a physiological stressor, and we hypothesized that feathers developed during this exposure period would reflect that physiological challenge (sensu Roulin et al. 2008), as melanin-based coloration is related to stress responsiveness (see Ducrest et al. 2008). Specifically, we predicted that the blue gray wing feathers (which appear to be structurally colored due to a reflectance peak in the UV range and are likely to possess predominately eumelanin pigments; Fargallo et al. 2007) and the brown tail feathers (which, based on spectral shape, seem to be pheomelanin based) would be less bright in experimental birds. Because neither nestling rectrices nor remiges are molted until after the bird's first breeding season, they would be able to signal male developmental quality during that first breeding season, yielding breeding consequences. Therefore, an increased level of stress may lower the quality of the feathers and may decrease an individual's ability to attract and retain a mate.

In sum, we examined several phenotypic responses of kestrels to exogenous CORT during the nestling period. In particular, we examined morphometrics, immunocompetence, and feather coloration, all of which can be related to survival or reproduction rates (McClung et al. 2004; Cichoń and Dubiec 2005; Moreno et al. 2005; Roulin and Altwegg 2007). This information allowed us to explore how low levels of simulated chronic stress during the kestrel nestling period affect not only the phenotype during development but also the phenotypic differences that may persist beyond the nestling period.

\section{Material and Methods}

\section{Housing and Feeding of Nestlings}

We used 19 nestling American kestrels taken from nest boxes located in Ada and Camas counties, Idaho. The ease of nest finding, the large nestling body size (which allows for ease of hormone implantation), the colorful feathers in males, and the relatively long nestling period make kestrels an appropriate study species for this investigation. At $13 \mathrm{~d}$ of age, we brought one male nestling per nest to Boise State University (females lack the blue gray wing coloration that we wanted to measure) and housed them with up to three other individuals in $15 \times 15$-cm straw-lined, open-topped cardboard boxes placed in $75 \times 75 \times 72-\mathrm{cm}$ wire cages. A heating lamp attached to the top of the cage provided warmth. The study was performed in captivity to avoid the differences in sibling competition and food-provisioning rates found in the field.

We fed birds until they were sated five times daily, at 0800 , 1100, 1400, 1700, and 1900 hours. Food consisted of 1-d-old feeder chickens. Five whole chicks were ground in a blender, and the resulting mixture was supplemented with approximately $3 \mathrm{~g}$ of multivitamins and powdered minerals (Quikon, Bocholt, Germany). We continued to feed kestrels until they ignored food for $10 \mathrm{~s}$. We measured the amount of food ingested to the nearest $0.1 \mathrm{~g}$ at every feeding. This regimen continued until the birds were $26 \mathrm{~d}$ old, after which we returned them to their original nest to fledge with their siblings. All work was performed under International Animal Care and Use Committee protocols 006-05-002 and 006-05-003.

\section{Implantation Procedure}

On arrival into the laboratory, nestlings alternately received either experimental (CORT-filled) or sham (empty) silastic implants. All implants were $20 \mathrm{~mm}$ long and were sealed at one end with silicone cement. Twenty-four hours before implantation, all implants were soaked in avian physiological saline solution. After administering a local anesthetic, we placed the implants under the skin on the medial side of the right leg. Seven days later, we removed the implants (Table 1). All incisions healed well, and no bird showed any permanent detrimental effects from the surgical procedures.

\section{Morphometric Analyses}

We measured bird mass to the nearest $0.1 \mathrm{~g}$ every morning before feeding. This allowed us to track weight gain during both the experimental treatment and the washout period after the implants were removed (Table 1). Morphometrics were taken on days 13,20, and 26 on both left and right wings and left and right tarsi. The absolute value of the difference between left and right structures is a measure of fluctuating asymmetry. 
Table 1: Time line of experimental procedures

\begin{tabular}{|c|c|c|c|c|c|}
\hline \multirow[b]{2}{*}{ Parameter of Interest } & \multicolumn{2}{|c|}{ Experimental Time Period } & \multicolumn{3}{|l|}{ Washout Period } \\
\hline & Day 13 & Day 19 & Day 20 & Day 25 & Day 26 \\
\hline Implantation & Implant administered & & Implant removed & & \\
\hline \multicolumn{6}{|l|}{ Morphometrics (with } \\
\hline weight taken daily) & Tarsus and wing & & Tarsus and wing & & Tarsus and wing \\
\hline \multicolumn{6}{|l|}{ Corticosterone and } \\
\hline humoral immunity & $\begin{array}{l}\text { 100- } \mu \mathrm{L} \text { baseline } \\
\text { blood sample } \\
\text { taken }\end{array}$ & & $\begin{array}{l}150-\mu \mathrm{L} \text { blood sample } \\
\text { taken }\end{array}$ & & $\begin{array}{l}200-\mu \mathrm{L} \text { blood sample } \\
\text { taken }\end{array}$ \\
\hline \multicolumn{6}{|l|}{ Cell-mediated } \\
\hline immunity & & $\begin{array}{l}\text { Challenge adminis- } \\
\text { tered to right wing }\end{array}$ & $\begin{array}{l}\text { Swelling of right } \\
\text { wing measured }\end{array}$ & $\begin{array}{l}\text { Challenge adminis- } \\
\text { tered to left wing }\end{array}$ & $\begin{array}{l}\text { Swelling of left wing } \\
\text { measured }\end{array}$ \\
\hline $\mathrm{H}: \mathrm{L}$ & & & $\begin{array}{l}\text { Duplicate blood } \\
\text { smears made }\end{array}$ & & $\begin{array}{l}\text { Duplicate blood } \\
\text { smears made }\end{array}$ \\
\hline Feather collection & & & & & Feathers removed \\
\hline Bird location & $\begin{array}{l}\text { Bird brought into } \\
\text { captivity }\end{array}$ & & & & $\begin{array}{l}\text { Bird placed back into } \\
\text { nest }\end{array}$ \\
\hline
\end{tabular}

Note. $\mathrm{H}: \mathrm{L}=$ ratio of heterophils to lymphocytes.

\section{Radioimmunoassay for Corticosterone}

Blood samples of $\sim 150$ and $\sim 200 \mu \mathrm{L}$ were taken within 3 min of entering the animal room immediately before the feeding at 0800 hours on days 20 and 26, respectively (Table 1). Blood was centrifuged for $1 \mathrm{~min}$ at $6,000 \mathrm{rpm}$, and the plasma was then collected and stored at $-20^{\circ} \mathrm{C}$ until analysis. This plasma was used for radioimmunoassay (RIA) of plasma total CORT and humoral immunity assessment.

The RIA protocol was modeled after Wingfield et al. (1992), using $35-100-\mu \mathrm{L}$ aliquots extracted using dichloromethane. All sample, standard curve, recovery count, and total count vials were counted in a Beckman LS6800 scintillation counter for 10 min or until $2 \%$ accuracy. Mean recovery rate was $84 \%$. Intra-assay variations were $3 \%$ and $2 \%$, with an interassay variation of $25 \%$.

\section{PHA-Induced Immune Response}

We injected PHA into the patagium of the right wing of 19d-old birds (Table 1). PHA causes measurable swelling at the site of injection, and a larger degree of swelling correlates to a more robust immune response. Each subject had a black dot drawn centrally on its patagium, with patagial thickness measured twice with a digital micrometer (Mitutoyo, model 293369). Directly under the black dot, we injected $50 \mu \mathrm{L}$ of phosphate-buffered saline (PBS) containing $50 \mu \mathrm{g}$ of PHA (Sigma). Twenty-four hours later, we measured the patagium at the site of the PHA injection. The difference in thickness between the pre- and postinjection measurements was indicative of immune cell infiltration. We injected PHA into the individual's left wing patagium when the bird was $25 \mathrm{~d}$ old and measured the resultant swelling $24 \mathrm{~h}$ later (Table 1). All work was conducted between 0830 and 1000 hours. Because of the potentially cu- mulative effect of PHA challenges, conclusions were drawn only between groups on either day 20 or 26 and not within subjects.

\section{Assessment of Humoral Immunity}

When a bird came into captivity ( $13 \mathrm{~d}$ old), we took a $100-\mu \mathrm{L}$ blood sample from the left alar vein and processed it for storage in a manner identical to that for blood taken for CORT assessment (Table 1). We then administered an intramuscular injection of $25 \mu \mathrm{g}$ of keyhole limpet hemocyanin (KLH; Sigma), a novel benign antigen, into the kestrel's right leg. The KLH was emulsified in $0.05 \mathrm{~mL}$ sterile deionized water and $0.05 \mathrm{~mL}$ incomplete Freund's adjuvant (Sigma). When the nestling was $26 \mathrm{~d}$ old, we took a blood sample of $\sim 200 \mu \mathrm{L}$ and processed it for storage, as described earlier. This assessment of humoral immunity $13 \mathrm{~d}$ postimmunization allowed for both a large antibody response (Butler and Dufty 2007) and enough time to return the individual to its nest in time to fledge.

To assess antibody quantity, we used a novel enzyme-linked immunosorbant assay (ELISA). Nunc ELISA plates (Fisher) were coated with $200 \mu \mathrm{L}$ of $0.5 \mathrm{mg} / \mathrm{mL} \mathrm{KLH}$ in sodium carbonate buffer and incubated at $37^{\circ} \mathrm{C}$ for $2 \mathrm{~h}$. After the liquid was removed, $200 \mu \mathrm{L}$ of blocking buffer (3\% powdered milk in $0.01 \mathrm{M}$ PBS) was added and left at room temperature for 2 h. The blocking buffer was then removed, and duplicates of $1: 400$ and $1: 800$ kestrel plasma dilution (in 3\% powdered milk and $0.01 \%$ sodium azide in $0.01 \mathrm{M} \mathrm{PBS}$ ) were added along with blank controls. The plates were incubated overnight at $4^{\circ} \mathrm{C}$. We washed the plates three times with $200 \mu \mathrm{L}$ PBS and $0.05 \%$ Tween 20 (Sigma). Because the wells were coated with $\mathrm{KLH}$, only KLH-specific kestrel antibody remained bound to the wells. Fifty microliters of horseradish peroxidase (HRP)labeled secondary antibody specific for avian IgG (Bethyl A140$110 \mathrm{P}$ ) diluted $1: 1,000$ in PBS, $0.05 \%$ Tween 20 , and $0.5 \%$ 
bovine serum albumin, was added and incubated at room temperature for $2 \mathrm{~h}$. Plates were then washed four times with PBS and $0.05 \%$ Tween 20 (Sigma). Each well received $50 \mu \mathrm{L}$ of the substrate tetramethylbenzidine (Sigma) and was left in the dark at room temperature for $30 \mathrm{~min}$. The colorometric reaction was stopped with $50 \mu \mathrm{L}$ of $0.5 \mathrm{M}$ sulfuric acid, and the optical density of the wells was read at a wavelength of $450 \mathrm{~nm}$. A higher optical density indicated a higher concentration of HRP, which was proportional to the amount of KLH-specific antibody present in the plasma sample. The optical density was measured by a BioRad Model 550 Microplate Reader and calculated using Microplate Manager PC 4.0. The difference between post- and preinoculation optical density within each bird was the variable used in all subsequent analyses. Intra-assay variation was $9 \%$.

\section{Determination of Heterophils: Lymphocytes}

At the time of blood collection on days 20 and 26 (Table 1), blood smears were made in duplicate. One to two drops of whole blood were placed on a microscope slide and spread to one cell layer thick. The slides air-dried for 30-60 min and then were fixed in methanol. Several months later, they were stained with Wright's Giemsa (Vol-U-Sol, Salt Late City, UT) stain. Slides were stained for $5 \mathrm{~min}$, transferred to buffer for $5 \mathrm{~min}$, and then subjected to 101 -s rinses.

Slides were viewed under a microscope at $\times 100$ with oil immersion. Leukocytes were counted until the total of basophils, eosinophils, monocytes, lymphocytes, and heterophils reached 100 . We calculated $\mathrm{H}: \mathrm{L}$ by dividing the number of heterophils by the number of lymphocytes.

\section{Feather Analysis}

On day 26 (Table 1), we plucked the blue gray secondary of the left wing, a dark brown central rectrix with a black subterminal band, and a brown central back contour feather from each bird, in which we observed no aberrant coloration. Feathers were stored in a plastic Ziploc bag until analysis. We used an Ocean Optics (Dunedin, FL) USB2000 spectrometer with a PX-2 pulsed xenon light source to collect reflectance for wavelengths between 300 and $700 \mathrm{~nm}$. We calibrated the spectrometer before each measurement with a Spectralon white reflectance standard, and we oriented the feather at $90^{\circ}$ from the spectrometer for each reading. There were three readings for each individual: (1) the blue of the secondary, (2) the dark brown of the rectrix, and (3) the brown of the contour feather. Reflectances were averaged over 5-nm intervals. We used these average values (wavelength bands) for statistical analyses.

\section{Statistical Analyses}

Unless specified otherwise, all analyses involved the response variable of interest as the dependent variable in a repeatedmeasures ANOVA, with treatment as a between-groups factor and age as a repeated factor. Using this template, we examined tarsus length, wing length, asymmetry for tarsus and wing lengths, circulating CORT titer, PHA response, and $\mathrm{H}$ : L. For humoral assessment, we ran an ANOVA with treatment as a between-groups factor, because humoral response to antigen was assessed at only one time point. We predicted that experimental birds would have higher CORT values on day 20, lower PHA-induced responses on day 20, and lower levels of antibody and higher $\mathrm{H}: \mathrm{L}$ on day 20, so we did not employ a Bonferroni correction, as has been suggested for analyses with specific predictions (Nakagawa 2004). Additionally, we further examined our data with a correlational perspective by regressing $\mathrm{H}: \mathrm{L}$, PHA response, and humoral immunity along CORT titer within each treatment group.

To examine food consumption, we summed the total mass of food consumed by an individual during period A (aged 14$19 \mathrm{~d}$ ) and period B (aged 21-26 d) and divided each value by 6 , the number of days in each period, to generate an average food consumption rate per day for each period. Similarly, we averaged the daily mass values for each bird during periods $\mathrm{A}$ and $\mathrm{B}$ to generate an average body mass value for each period. Because our goal was to look for differences between periods and not among days, we performed a repeated-measures ANOVA with treatment as a between-groups factor, period as the repeated factor, and a treatment-by-period interaction.

Finally, to calculate the ultraviolet/blue chroma of the secondary feather, we divided the proportion of the brightness from the 320- to $400-\mathrm{nm}$ range by the total brightness from 320 to $700 \mathrm{~nm}$. We then examined differences in chroma between treatment groups with a one-factor ANOVA. Because brown feathers do not have a specific chromatic region, we compared the total brightness between treatment groups. To test for treatment differences in hue (wavelength of maximum reflectance), we used a one-factor ANOVA. All data were analyzed in SAS 9.1, and all means are reported \pm SE.

\section{Results}

\section{Corticosterone}

Ten samples had values below the detectable limit (two CORT implanted, eight sham implanted). So as not to bias our analyses by the exclusion of the lowest values, we opted to assign the lowest detected value $(0.123 \mathrm{ng} / \mathrm{mL})$ to this group of data, thereby giving values to samples below the detectable limit. Doing so increased the statistical power of our analysis while remaining conservative with respect to the predicted outcome. Sham-implanted birds had lower levels of plasma CORT than did CORT-implanted birds $\left(F_{1,17}=5.17, P=0.034\right.$; Fig. 1). There was no hormone treatment-by-day interaction $\left(F_{1,17}=2.46, P=0.135\right)$ or day effect $\left(F_{1,17}=0.19, \quad P=\right.$ 0.665). A least squares means comparison of groups showed that CORT-implanted birds had higher CORT levels at day 20 $(P=0.0045)$, while there was no difference between groups on day $26(P=0.3334)$. 


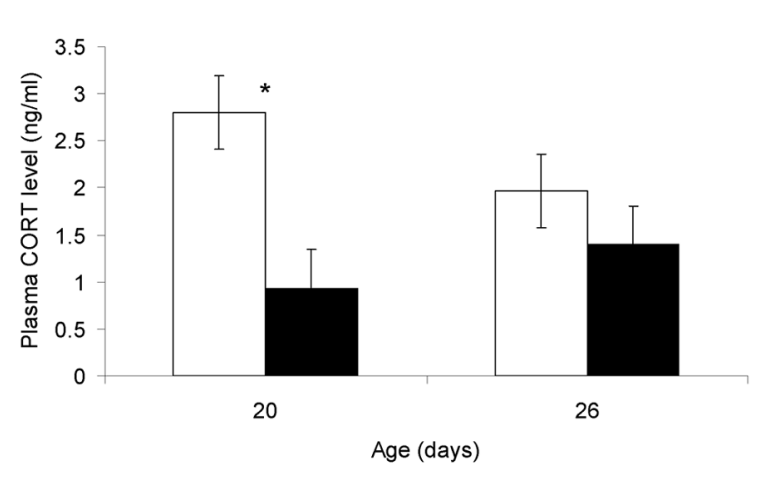

Figure 1. Baseline corticosterone (CORT) levels of kestrels as a function of age. Birds with CORT implants (open bars) showed a higher level of plasma CORT (average \pm SE) on day 20 than did control birds (solid bars; $P=0.0045$ ). However, on day 26, both groups had similar levels of plasma CORT. An asterisk denotes a significant difference based on an $\alpha=0.05$.

\section{Morphometrics and Feeding}

Kestrels did not differ in amount of food ingested $\left(F_{1,17}=\right.$ $0.18, P=0.68)$, body mass $\left(F_{1,17}=0.79, P=0.39\right)$, or amount of food ingested per mass of the bird $\left(F_{1,17}=0.00, P=0.98\right)$ based on hormonal treatment, and interaction terms were nonsignificant (both $P>0.25$ ). Birds ingested more during period A than during period B (see "Statistical Analyses"; $F_{1,17}=$ 7.85, $P=0.012$ ), birds weighed significantly more during pe$\operatorname{riod} \mathrm{B}\left(F_{1,17}=44.59, P<0.0001\right)$ than during period $\mathrm{A}$, and birds ingested less food per mass of the bird during period $\mathrm{B}$ than during period $\mathrm{A}\left(F_{1,17}=36.19, P<0.0001\right)$.

There were no main effects of treatment on tarsus, wing, asymmetry of tarsus, or asymmetry of wing (all $P>0.2$ ), and there were no significant interactions (all $P>0.14$ ) between treatment and age for tarsus, asymmetry of tarsus, and asymmetry of wing (four measurements were missing for day 26). However, there was a significant interaction between treatment and age for wing length $\left(F_{2,30}=8.14, P=0.0015\right)$. When comparing the least squares means of experimental and control units on days 13,20 , and 26 , we found differences on day 13 $(P=0.039)$, day $20(P=0.013)$, and day $26(P=0.007)$, with CORT-treated birds having longer wings on day 13 but shorter wings on days 20 and 26 (Fig. 2).

\section{Immune Function}

There was no significant effect of CORT treatment on the PHAinduced swelling response $\left(F_{1,17}=3.54, P=0.077\right)$ and no significant interaction between treatment and age $\left(F_{1,17}=2.27\right.$, $P=0.15)$, but there was an effect of age $\left(F_{1,17}=22.58, P=\right.$ $0.0002)$. We then used a least squares means comparison and found a difference between treatments on day 26, with CORTtreated birds showing a significantly greater amount of swelling $(P=0.035$; Fig. 3).

Because of a limited amount of plasma, only one IgG ELISA could be run to assess differences between CORT- and shamimplanted groups. We used 10 individuals, with five from each treatment. Hormone treatment did not significantly affect antibody production $\left(F_{1,8}=0.09, P=0.77\right)$; however, we acknowledge that the limited sample size of this metric may have increased our likelihood of committing a Type II error.

Neither hormone treatment $\left(F_{1,17}=0.12, P=0.73\right)$ nor age $\left(F_{1,17}=3.02, P=0.10\right)$ affected $\mathrm{H}: \mathrm{L}$ ratio, and there was no interaction between treatment and age $\left(F_{1,17}=2.27, P=0.15\right)$. We also examined correlational relationships between CORT and immune response by using regressions. Although regressions were not significant for most immune variables (all $P>$ 0.2 ), CORT was negatively related to PHA response for shamimplanted birds when they were $20 \mathrm{~d}$ old $\left(F_{1,7}=9.18, P=\right.$ 0.019; Fig. 4).

\section{Feathers}

Hormonal treatment did not affect brightness of the brown tail $\left(F_{1,17}=0.41, \quad P=0.53\right)$, the brown contour $\left(F_{1,17}=0.87\right.$, $P=0.36)$, or the ultraviolet/blue chroma of the wing feathers $\left(F_{1,17}=0.98, P=0.34\right)$.

\section{Discussion}

We simulated a low-level chronic stressor and measured its effects on kestrel development. To our knowledge, this is the first such study regarding avian subjects, as other studies model acute long-term or repeated stressors (Spencer et al. 2003; Moe et al. 2004). We examined the subtle effects produced by a small but significant increase in baseline CORT over a relatively short period. We found that feather growth decreased and that immunoresponsiveness increased within CORT-treated individuals, but these differences manifested several days after the end of increased CORT exposure.

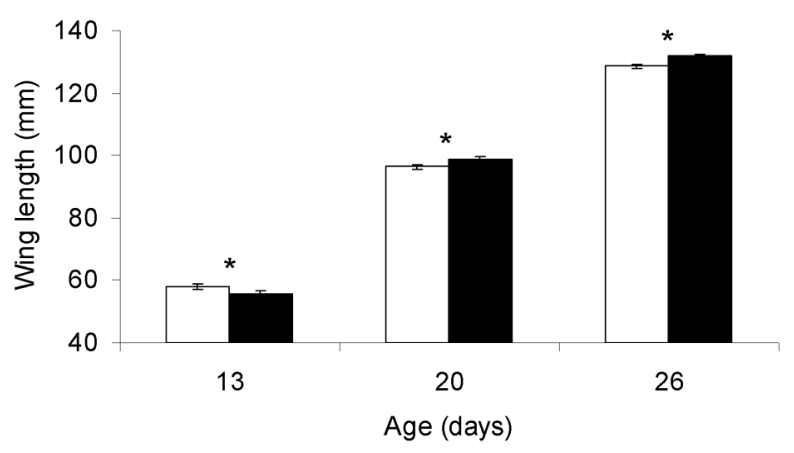

Figure 2. Wing length of kestrels as a function of age. Control birds (solid bars) had shorter wings than did experimental birds (open bars) on day $13(P=0.039)$. However, on days 20 and 26 , control birds had longer wings than did experimental birds $(P=0.013$ and $P=$ 0.007 , respectively). An asterisk denotes a significant difference based on $\alpha=0.05$. 


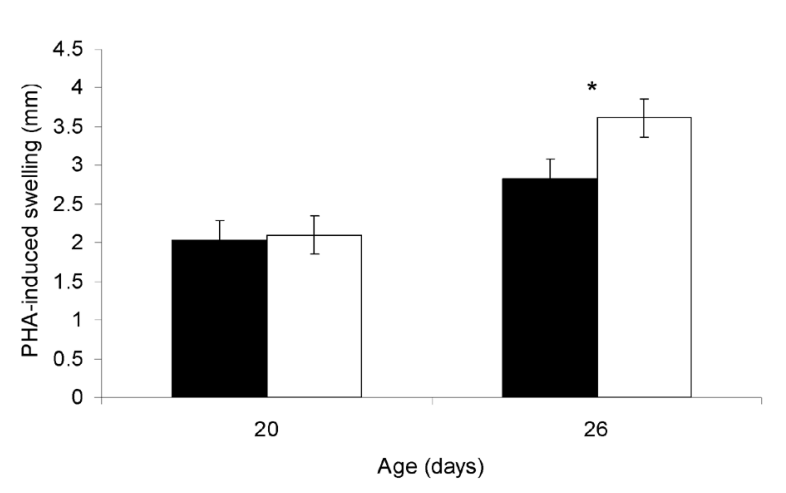

Figure 3. Immune response of kestrels as a function of age. Amount of phytohemagglutinin-induced swelling was equal at day 20 , but experimental birds (open bars) showed an increased amount of swelling $(3.62 \pm 0.24 \mathrm{~mm})$ compared with that of controls (solid bars; $2.83 \pm 0.25 \mathrm{~mm})$ on day $26(P=0.035)$. An asterisk denotes a significant difference based on an $\alpha=0.05$.

\section{Corticosterone}

Kestrel nestlings at day 20 generally have baseline plasma CORT levels of approximately $2 \mathrm{ng} / \mathrm{mL}$ (but see Müller et al. 2009 for data regarding Eurasian kestrels Falco tinnunculus), while under acute stress, birds of this age generally exhibit plasma CORT concentrations of more than $10 \mathrm{ng} / \mathrm{mL}$ (Love et al. 2003). We expected circulating CORT concentrations in our subjects to be fairly low, as our birds did not experience food restriction that can result in increased CORT circulation (Kitaysky et al. 1999; Corbel and Groscolas 2008). In this experiment, the control birds had levels of about $1 \mathrm{ng} / \mathrm{mL}$, while the experimental birds had levels of $3 \mathrm{ng} / \mathrm{mL}$, so that experimental birds exhibited an approximately threefold increase in mean CORT values. This increase of $2 \mathrm{ng} / \mathrm{mL}$ is small in absolute terms, but it nonetheless represents a significant increase in plasma CORT levels. Additionally, it has been shown that similar implants in dark-eyed juncos (Junco hyemalis) resulted in a fivefold increase in CORT during the first $18 \mathrm{~h}$, followed by a one- to twofold increase compared with that of controls during the subsequent $3 \mathrm{~d}$ (Gray et al. 1990). If a similar profile existed in the kestrels, then their initial exposure to CORT would have been higher than what we measured a week after implantation. Nonetheless, because we found developmental differences between the two treatment groups that differed only in exposure to a small but significant increase in circulating corticosterone levels, we concluded that the modest increase in baseline CORT levels did constitute an effective simulation of a chronic low-level stressor.

\section{Immune Function}

We found that there were no treatment-based differences between groups in cutaneous immunity levels and $\mathrm{H}: \mathrm{L}$ during treatment, contrary to other studies that experimentally manipulated either CORT titer (Bourgeon and Raclot 2006) or stress levels (Laudenslager et al. 1988; Moynihan et al. 1990; Saino et al. 2003; but see Cyr et al. 2007) to demonstrate that
CORT is immunosuppressive (reviewed in Buchanan 2000). There are several possible explanations for this. First, the levels of CORT, while different between groups, may not have been high enough or sustained for long enough to elicit an immunosuppressive result (see Buchanan 2000). Second, the CORT treatments we used did not covary with, nor were they caused by, a restricted diet (Saino et al. 2003). Therefore, our findings do not inherently contradict previous findings $(\mathrm{Bu}-$ chanan 2000; Saino et al. 2003) that chronically elevated CORT is immunosuppressive, as ad lib. food, in conjunction with low levels of chronically elevated CORT, did not reduce immune function in developing nestlings.

We did find that there was a negative relationship between CORT titer and PHA response in sham-implanted birds that were $20 \mathrm{~d}$ old. This finding suggests that individuals that naturally maintain higher levels of circulating CORT may also have reduced levels of cutaneous immune function. The question of whether natural variation in baseline CORT and cutaneous immune function affects life-history traits, such as recruitment (Cichon and Dubiec 2005), would benefit from additional investigation, as the results presented here are correlational.

The increase in cutaneous immunoresponsiveness in experimental subjects is consistent with CORT's stimulatory effect when elevated during short-lived stressors of modest intensity but not during chronic high-level stress (Sapolsky et al. 2000). The differences in response probably arise from changes in the number and types of CORT receptors activated (Sapolsky et al. 2000). These data suggest that the low-level stimulation of the HPA axis produced in this study enhances immunocompetence after hormone exposure. Furthermore, immunocompetence (Moreno et al. 2005) and, specifically, degree of cutaneous immunity (Cichoń and Dubiec 2005) are correlated with recruitment to the breeding population, so the higher levels of cutaneous immunity in experimental subjects may be associated with increased recruitment. However, we do not have any recapture data from these nestlings and are unable to examine this prediction.

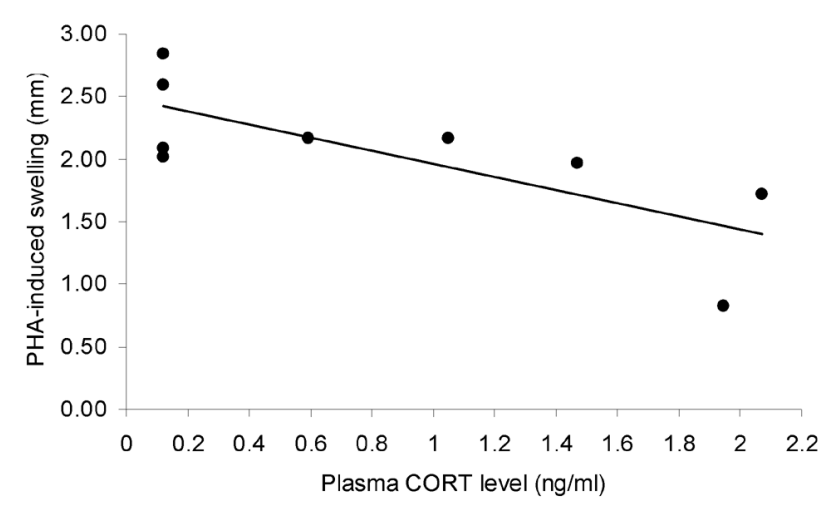

Figure 4. Phytohemagglutinin-induced immune response of kestrels as a function of circulating corticosterone (CORT) titer. Twenty-day-old kestrels that had received sham implants showed a negative relationship between CORT titer and phytohemagglutinin (PHA) response (adjusted $R^{2}=0.51, P=0.019$ ). 
Feathers and Morphometrics

Hormonal treatment also affected feather development. The reduced primary length on days 20 and 26 suggests that not as many resources could be allocated toward developing feathers. In kestrels, short-term food restriction during the nestling period results in decreased contour feather brightness (Marzot 2007). Additionally, length of wing feathers in kestrels is correlated with bare-part coloration (Bostrom and Ritchison 2006), which may be a condition-dependent trait (Bortolotti et al. 1996; Negro et al. 1998). However, contrary to findings in other studies (Roulin et al. 2008), we did not see an effec $^{+}$ of hormonal treatment on feather coloration, which suggests that the blue gray coloration of kestrels is not condition dependent, although further work is needed to verify this suggestion.

\section{Conclusion}

Our data suggest that kestrels experience modest phenotypic effects in response to low levels of physiological stress in the nestling stage. However, the birds in this study experienced elevated CORT titer while still receiving an ad lib. diet. It is possible that diet-induced stress in nature may result in a different outcome as resources become more limited. Dietarily: stressed European shags (Phalacrocorax aristoltelis) were able to maintain structural growth but at the cost of resting metabolic rate, muscle mass, and body temperature (Moe et al. 2004) So, if increased levels of CORT were accompanied by lower availability of resources, it is possible that birds would shunt resources away from immunity (Soler et al. 2003) and toward more immediately important developmental parameters, such as growth. An investigation involving both diet restriction and CORT implants would be useful to examine how neonatal stres? and dietary needs interact to affect avian development.

Overall, our results suggest that kestrel nestlings experiencr. subtle but measurable and probably biologically important developmental effects in response to a weeklong modest, sustained increase in CORT titer. Despite the possible initial surge ir CORT release from the silastic implants (Gray et al. 1990), the small $(2 \mathrm{ng} / \mathrm{mL}) 7$-d sustained increase in CORT resulted in measurable effects on immune function and feather length $\epsilon$ $\mathrm{d}$ after exposure to exogenous CORT ended. These results highlight two important findings. First, small and continuous stressors during the nestling stage may affect development of im mune function and feathers, both of which may affect fitness. Second, it may behoove researchers to measure their subjects several times over the course of a study, as we found evidencr for the manifestation of effects almost a week after our experimental manipulation had ended.

\section{Acknowledgments}

We would like to thank Steve Schoech and Eli Bridge for help in measuring feather coloration and Eli for assisting in th $\rightarrow$ analysis of coloration data. M. Belluzzo, K. Donohue, E. Hal- lingstad, A. LaCava, V. Marzot, J. Newman, and A. Stillman all provided help with husbandry and fieldwork. Idaho Power Company and Micron Technologies provided logistical resources. Several anonymous reviewers provided valuable input regarding the improvement of this manuscript. Funding was provided by Boise State University's Department of Biology, the Raptor Research Center, and the National Science Foundation's Research Coordination Network Exchange Visit.

\section{Literature Cited}

Amat J.A., E. Aguilera, and G.H. Visser. 2007. Energetic and developmental costs of mounting an immune response in greenfinches (Carduelis chloris). Ecol Res 22:282-287.

$\rightarrow$ Andersson S., J. Örnborg, and M. Andersson. 1998. Ultraviolet sexual dimorphism and assortative mating in blue tits. Proc R Soc B 265:445-450.

Apanius V. 1998. Stress and immune defense. Pp. 133-153 in A.P. Møller, M. Milinski, and P.J.B. Slater, eds. Stress and Behavior: Advances in the Study of Behavior. Vol. 27. Academic Press, San Diego, CA.

Balmford A., I.L. Jones, and A.L.R. Thomas. 1993. On avian symmetry: evidence of natural selection for symmetrical tails and wings in birds. Proc R Soc B 252:245-251.

$\rightarrow$ Bortolotti G.R., J.J. Negro, J.L. Tella, T.A. Marchant, and D.M. Bird. 1996. Sexual dichromatism in birds independent of diet, parasites, and androgens. Proc R Soc B 263:1171-1176.

Bostrom M.R. and G. Ritchison. 2006. Possible relationships between morphology, territory quality, and skin color of American kestrels. J Field Ornithol 77:392-398.

$\rightarrow$ Bourgeon S. and T. Raclot. 2006. Corticosterone selectively decreases humoral immunity in female eiders during incubation. J Exp Biol 209:4957-4965.

$\rightarrow$ Buchanan K.L. 2000. Stress and the evolution of conditiondependent signals. Trends Ecol Evol 15:156-160.

$\rightarrow$ Butler M.W. and A.M. Dufty Jr. 2007. Nestling immunocompetence is affected by captivity but not investigator handling. Condor 109:920-928.

$\rightarrow$ Cichoń M. and A. Dubiec. 2005. Cell-mediated immunity predicts the probability of local recruitment in nestling blue tits. J Evol Biol 18:962-966.

Clarke G.M. 1995. Relationships between developmental stability and fitness: application for conservation biology. Conserv Biol 9:18-24.

Corbel H. and R. Groscolas. 2008. A role for corticosterone and food restriction in the fledging of nestling white storks. Horm Behav 53:557-566.

$\rightarrow$ Cyr N.E., K. Earle, C. Tam, and L.M. Romero. 2007. The effect of chronic psychological stress on corticosterone, plasma metabolites, and immune responsiveness in European starlings. Gen Comp Endocrinol 154:59-66.

$\rightarrow$ Dawson R.D. and M.T. Bidwell. 2005. Dietary calcium limits size and growth of nestling tree swallows Tachycineta bicolor in a non-acidified landscape. J Avian Biol 36:127-134.

Doucet S.M. and R. Montgomerie. 2003. Multiple sexual ornaments in satin bowerbirds: ultraviolet plumage and bowers 
signal different aspects of male quality. Behav Ecol 14:503509.

$\rightarrow$ Ducrest A.L., L. Keller, and A. Roulin. 2008. Pleiotropy in the melanocortin system, coloration and behavioural syndromes. Trends Ecol Evol 23:502-510.

$\rightarrow$ Dufty A.M., Jr., J. Clobert, and A.P. Møller. 2002. Hormones, developmental plasticity, and adaptation. Trends Ecol Evo $\rightarrow$ 17:190-196.

$\rightarrow$ Ekblom R., S.A. Sæther, D. Hasselquist, D. Hannersjö, P. Fiske, J.A. Kålås, and J. Höglund. 2005. Female choice and male humoral immune response in the lekking great snipe ( $\mathrm{Gal}$ linago media). Behav Ecol 16:346-351.

$\rightarrow$ Fargallo J.A., T. Laaksonen, E. Korpimäki, and K. Wakamatsu. 2007. A melanin-based trait reflects environmental growtl $\rightarrow$ conditions of nestling male Eurasian kestrels. Evol Ecol 21: 157-171.

$\rightarrow$ Garvin J.C., P.O. Dunn, L.A. Whittingham, D.A. Steeber, and D. Hasselquist. 2008. Do male ornaments signal immunit $\rightarrow$ in the common yellowthroat? Behav Ecol 19:54-60.

$\rightarrow$ Gray J.M., D. Yarian, and M. Ramenofsky. 1990. Corticosterone, foraging behavior, and metabolism in dark-eyed juncos, Junco hyemalis. Gen Comp Endocrinol 79:375-384.

Gross W.B. and P.B. Siegel. 1982. Socialization as a factor ir resistance to infection, feed efficiency, and response to antigen in chickens. Am J Vet Res 43:2010-2012.

$\rightarrow$ Hanssen S.A., D. Hasselquist, I. Folstad, and K.E. Erikstad. 2004. Costs of immunity: immune responsiveness reducer survival in a vertebrate. Proc R Soc B 271:925-930.

$\rightarrow$ Hasselquist D., J.A. Marsh, P.W. Sherman, and J.C. Wingfield. 1999. Is avian humoral immunocompetence suppressed by testosterone? Behav Ecol Sociobiol 45:167-175.

$\rightarrow$ Hayward L.S. and J.C. Wingfield. 2004. Maternal corticosterone is transferred to avian yolk and may alter offspring growth and adult phenotype. Gen Comp Endocrinol 135:365-371.

$\rightarrow$ Ilmonen P., D. Hasselquist, Å. Langefors, and J. Wiehn. 2003. Stress, immunocompetence, and leukocyte profiles of pied flycatchers in relation to brood size manipulation. Oecologia 136:148-154.

$\rightarrow$ Kitaysky A.S., E.V. Kitaiskaia, J.K. Piatt, and J.C. Wingfield. 2003. Benefits and costs of increased levels of corticosterone in seabird chicks. Horm Behav 43:140-149.

$\rightarrow$ Kitaysky A.S., J.F. Piatt, J.C. Wingfield, and M. Romano. 1999. The adrenocortical stress-response of black-legged kittiwakt chicks in relation to dietary restrictions. J Comp Physiol B 169:303-310.

$\rightarrow$ Kitaysky A.S., J.C. Wingfield, and J.F. Piatt. 2001. Corticosterone facilitates begging and affects resource allocation in the black-legged kittiwake. Behav Ecol 12:619-625.

$\rightarrow$ Laudenslager M.L., M. Fleshner, P. Hofstadter, P.E. Held, L. Simons, and S.F. Maier. 1988. Suppression of specific anti $\rightarrow$ body production by inescapable shock: stability under varying conditions. Brain Behav Immun 2:92-101.

$\rightarrow$ Love O.P., D.M. Bird, and L.J. Shutt. 2003. Plasma corticosterone in American kestrel siblings: effects of age, hatchin $\rightarrow$ order, and hatching asynchrony. Horm Behav 43:480-488.

$\rightarrow$ Martin L.B., II, P. Han, J. Lewittes, J.R. Kuhlman, K.C. Klasing, and M. Wikelski. 2006. Phytohemagglutinin-induced skin swelling in birds: histological support for a classic immunoecological technique. Funct Ecol 20:290-299.

Marzot V. 2007. Early Food Restriction and Phenotypic Development in Captive American Kestrels (Falco sparverius). MS thesis. Boise State University.

$\rightarrow$ McClung M.R., P.J. Seddon, M. Massaro, and A.N. Setiawan. 2004. Nature-based tourism impacts on yellow-eyed penguins Megadyptes antipodes: does unregulated visitor access affect fledging weight and juvenile survival? Biol Conserv 119:279-285.

$\rightarrow$ Metcalfe N.B. and P. Monaghan. 2001. Compensation for a bad start: grow now, pay later? Trends Ecol Evol 16:254-261.

Moe B., S. Brunvoll, D. Mork, T.E. Brobakk, and C. Bech. 2004. Developmental plasticity of physiology and morphology in diet-restricted European shag nestlings (Phalacrocorax aristoltelis). J Exp Biol 207:4067-4076.

$\rightarrow$ Moreno J., S. Merino, J.J. Sanz, E. Arriero, J. Morales, and G. Tomás. 2005. Nestling cell-mediated immune response, body mass, and hatching date as predictors of local recruitment in the pied flycatcher Ficedula hypoleuca. J Avian Biol 36: 251-260.

$\rightarrow$ Moynihan J.A., R. Ader, L.J. Grota, T.R. Schachtman, and N. Cohen. 1990. The effects of stress on the development of immunological memory following low-dose antigen priming in mice. Brain Behav Immun 4:1-12.

$\rightarrow$ Müller C., S. Jenni-Eiermann, and L. Jenni. 2009. Effects of a short period of elevated circulating corticosterone on postnatal growth in free-living Eurasian kestrels Falco tinnunculus. J Exp Biol 212:1405-1412.

$\rightarrow$ Nakagawa S. 2004. A farewell to Bonferroni: the problems of low statistical power and publication bias. Behav Ecol 15: 1044-1045.

$\rightarrow$ Navarro C., A. Marzal, F. de Lope, and A.P. Møller. 2003. Dynamics of an immune response in house sparrows Passer domesticus in relation to time of day, body condition, and blood parasite infection. Oikos 101:291-298.

$\rightarrow$ Negro J.J., G.R. Bortolotti, J.L. Tella, K.J. Fernie, and D.M. Bird. 1998. Regulation of integumentary colour and plasma carotenoids in American kestrels consistent with sexual selection theory. Funct Ecol 12:307-312.

$\rightarrow$ Nowicki S., W.A. Searcy, and S. Peters. 2002. Brain development, song learning and mate choice in birds: a review and experimental test of the "nutritional stress hypothesis." J Comp Physiol A 188:1003-1014.

$\rightarrow$ Ots I., A. Murumägi, and P. Hõrak. 1998. Haematological health state indices of reproducing great tits: methodology and sources of natural variation. Funct Ecol 12:700-707.

Poiani A., A.R. Goldsmith, and M.R. Evans. 2000. Ectoparasites of house sparrows (Passer domesticus): an experimental test of the immunocompetence handicap hypothesis and a new model. Behav Ecol Sociobiol 47:230-242.

Roulin A., B. Almasi, A. Rossi-Pedruzzi, A.L. Ducrest, K. Wakamutsu, I. Miksik, J.D. Blount, S. Jenni-Eiermann, and L. Jenni. 2008. Corticosterone mediates the condition- 
dependent component of melanin-based coloration. Anim Behav 75:1351-1358.

$\rightarrow$ Roulin A. and R. Altwegg. 2007. Breeding rate is associatec $\rightarrow$ with pheomelanism in male and with eumelanism in female barn owls. Behav Ecol 18:563-570.

$\rightarrow$ Saino N., C. Suffritti, R. Martinelli, D. Rubolini, and A.P. Møller. 2003. Immune response covaries with corticosterone plasma levels under experimentally stressful conditions ir nestling barn swallows (Hirundo rustica). Behav Ecol 14:318325.

$\rightarrow$ Salvante K. 2006. Techniques for studying integrated immune function in birds. Auk 123:575-586.

$\rightarrow$ Sapolsky R.M., L.M. Romero, and A.U. Munck. 2000. How dc glucocorticoids influence stress responses? integrating permissive, suppressive, stimulatory, and preparative actions. Endocr Rev 21:55-89.

$\rightarrow$ Sockman K.W. and H. Schwabl. 2001. Plasma corticosterone in nestling American kestrels: effects of age, handling stress. yolk androgens, and body condition. Gen Comp Endocrinor 122:205-212.

$\rightarrow$ Soler J.J., L. de Neve, T. Pérez-Contreras, M. Soler, and G. Sorci. 2003. Trade-off between immunocompetence and growth in magpies: an experimental study. Proc R Soc B 270:241-248.

$\rightarrow$ Spencer K.A., K.L. Buchanan, A.R. Goldsmith, and C.K. Catchpole. 2003. Song as an honest signal of developmental stress in the zebra finch (Taeniopygia guttata). Horm Behav $44 . \rightarrow$ 132-139.

$\rightarrow$ Spencer K.A. and S. Verhulst. 2007. Delayed behavioral effects of postnatal exposure to corticosterone in the zebra finch (Taeniopygia guttata). Horm Behav 51:273-280.

Spencer K.A., J.H. Wimpenny, K.L. Buchanan, P.G. Lovell, A.R. Goldsmith, and C.K. Catchpole. 2005. Developmental stress affects the attractiveness of male song and female choice in the zebra finch (Taeniopygia guttata). Behav Ecol Sociobiol 58:423-428.

$\rightarrow$ Suorsa P., H. Helle, V. Koivunen, E. Huhta, A. Nikula, and H. Hakkarainen. 2004. Effects of forest patch size on physiological stress and immunocompetence in an area-sensitive passerine, the Eurasian treecreeper (Certhia familiaris): an experiment. Proc R Soc B 271:435-440.

$\rightarrow$ Tschirren B., P.S. Fitze, and H. Richner. 2003. Sexual dimorphism in susceptibility to parasites and cell-mediated immunity in great tit nestlings. J Anim Ecol 72:839-845.

$\rightarrow$ Watson P.J. and R. Thornhill. 1994. Fluctuating asymmetry and sexual selection. Trends Ecol Evol 9:21-25.

$\rightarrow$ Whitaker S. and J. Fair. 2002. The costs of immunological challenge to developing mountain chickadees, Poecile gambeli, in the wild. Oikos 99:161-165.

Wingfield J.C., D.L. Maney, C.W. Bruener, J.D. Jacobs, S. Lynn, M. Ramenofsky, and R.D. Richardson. 1998. Ecological bases of hormone-behavior interactions: the "emergency life history stage." Am Zool 38:191-204.

$\rightarrow$ Wingfield J.C., C.M. Vleck, and M.C. Moore. 1992. Seasonal changes of the adrenocortical response to stress in birds of the Sonoran Desert. J Exp Zool 264:419-428. 